\title{
Quantitative monitoring of surface movements on active landslides by multi-temporal, high-resolution X-Band SAR amplitude information: Preliminary results
}

\author{
M. Mulas \& A. Corsini \\ Department of Chemical and Geological Sciences, University of Modena and Reggio Emilia, Modena, Italy \\ G. Cuozzo, M. Callegari \& B. Thiebes \\ EURAC Research, Institute for Applied Remote Sensing, Bolzano, Italy
}

V. Mair

Office for Geology and Building Materials Testing, Autonomous Province of Bolzano, Italy

\begin{abstract}
Multi-temporal image cross-correlation is a method for tracking moving features and can there-fore be used for quantitative assessments of surface displacements. Accuracies of up to 1/8th of the original image geometric resolution can be achieved. We present the results of an analysis carried out on Corvara landslide located in the Italian Dolomites. Image offset-tracking was applied to CosmoSky-Med amplitude images acquired between October 2013 and August 2015. The presence of a validation dataset consisting of periodical GPS surveys carried out on 16 benchmarks represents an ideal opportunity to test the applicability of SAR-based image cross-correlation for landslide monitoring. Despite the relative low accuracy of the results amplitude-based offset-tracking proved to be beneficial due to the ability of this method to capture large displacements. In particular the results evidence its complementarity with respect to multi-temporal interferometry that is confined to slow displacements along E-W directions.
\end{abstract}

\section{INTRODUCTION}

Monitoring displacements occurring on landslides characterized by wide areal extensions and heterogeneous rates of movement is a difficult task and not all technologies are suitable for it. This paper highlights the application of the Offset-Tracking (OT) method based on Synthetic Aperture Radar (SAR) amplitude images for landslide monitoring. OT or 2D image cross-correlation of high-resolution remote sensed scenes or digital elevation models represents a valuable technique for monitoring unstable slopes (Casu et al. 2011, Daehne \& Corsini 2013, Manconi et al. 2014, Shi et al. 2015, Singleton et al. 2014). Such method represents a useful integration of advanced SAR multi-interferometry method for monitoring the parts of a landslide that are characterized by high rates of movement and low temporal correlation.

The paper includes the preliminary results obtained at the Corvara landslide where this technique has been used to track Corner Reflectors (CR). Validation has been carried out by using high precision Differential-Global Positioning System (D-GPS) surveys.

\section{CASE STUDY AND DATASET}

\subsection{Corvara landslide}

Corvara landslide is an active slow-moving landslide located up-slope the homonym village in the Dolomites area (NE Italy). Since it is a widely investigated phenomenon whose geometries have been clearly defined by land surveys and instrumental monitoring (Corsini et al. 1999, Corsini et al. 2001, Corsini et al. 2005), it represents the ideal case study for testing novel monitoring techniques and technologies (Corsini et al. 2012, Mulas et al. 2012, Mulas et al. 2015b). The landslide has been classified as an active, slow-moving deep-seated rotational earthslide-earthflow with active slip surfaces located at depths of up to $48 \mathrm{~m}$. The bedrock of the area consist of weak formations of the Triassic characterized by the alternation between sub meter strata of hard rocks and weak rocks (Corsini et al. 2000).

\section{$2.2 S A R$ and D-GPS dataset}

Monitoring data collected in the period 20012008 (Corsini et al. 2012) highlight a wide range 
of displacements rates within the landslide area ranging from few centimeters per year in the accumulation zone up to meters per year in the central track zone. During winter 2013-2014, particularly wet conditions and mild temperatures before the advent of snow cover, determined the conditions for the re-activation of one source zone of the landslide (Corsini et al. 2015).

In the period from October 2013 to August 2015, CosmoSky-Med (CSK) X-band SAR descending scenes with $3 \mathrm{~m}$ ground resolution (STRIPMAP HIMAGE mode) have been scheduled and acquired with a temporal resolution of 16 days.

Bi-weekly D-GPS monitoring tasks (Mulas et al. 2015a), synchronous to each SAR acquisition, allowed measuring the acceleration phase of winter 2013-2014 with displacement rates up to 10 meters in one month in the track zone. This D-GPS dataset has served as validation basis for the OT analysis based on the CSK dataset.

\section{METHOD}

The OT analysis of CR presented in this work has been performed using CSK acquisitions covering the period from October 2013 to Augusts 2015. The following elaboration steps have been undertaken: i) derivation from the original SAR SingleLook-Complex (SLC) acquisition of co-registered and geocoded amplitude images (Fig. 2); ii) crosscorrelation analysis focused on point-like targets identified on the landslide area by 16 CRs (Fig. 1). The deployed CR have been designed for forking with X-Band SAR sensors with the following characteristics: aluminum trihedral with $56 \mathrm{~cm}$ face-lengths installed over 2 meters height poles to stand out of the snow. The analysis has been performed using the Image Correlation Software CIAS, previously used for optical images (Kääb \& Vollmer 2000, Heid \& Kääb 2012). The expected error of the method is approximately 1/8th of the image geometric resolution. Given the spatial $3 \mathrm{~m}$ resolution the CSK dataset, it corresponds to $0.375 \mathrm{~m}$. Given a pair of geocoded images the CIAS software computes using a spatial moving window a Normalized Cross-Correlation (NCC) and an orientation correlation (NCC-O). The software outputs consist in an ASCII list of coordinates offsets and on the related correlation value (Kääb 2012).

The validation was performed by computing the difference between the planar displacement recorded by offset-tracking technique and the planar component of displacement measured in the same point with high precision D-GPS surveys. As shown in Figure 1b each CR is equipped with a GPS appendix designed for SAR measurements validation (Mair at al. Submitted). GPS surveys were carried out in static mode (with at least 2 hours of measurement in each point) with processing carried out using a permanent GPS station located $2.7 \mathrm{~km}$ away from the site as reference. This provided a position solutions with a mean accuracy in the order of $1 \times 10^{-3} \mathrm{~m}$.

\section{RESULTS}

In Figure 2 a change detection map is presented where SAR geocoded amplitude images have been

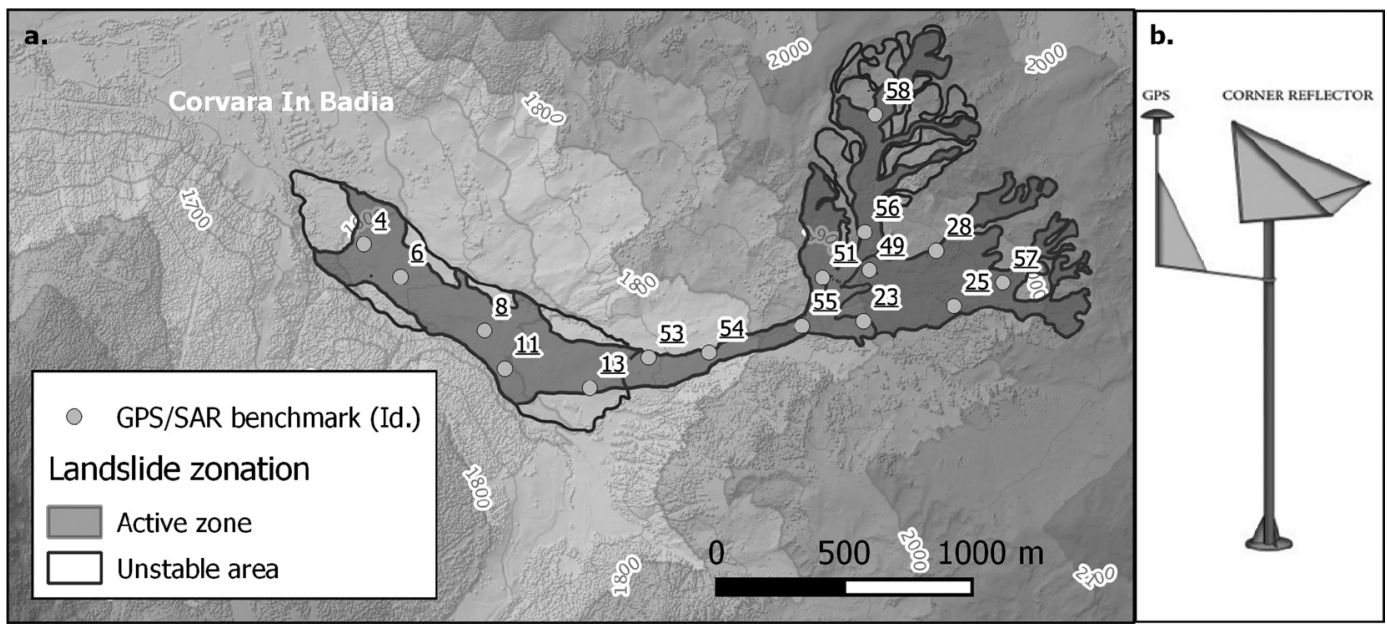

Figure 1. a) Zonation of the Corvara landslide and location of benchmarks equipped with Corner Reflectors; b) Scheme of the SAR corner reflectors deployed designed for GPS validation. 


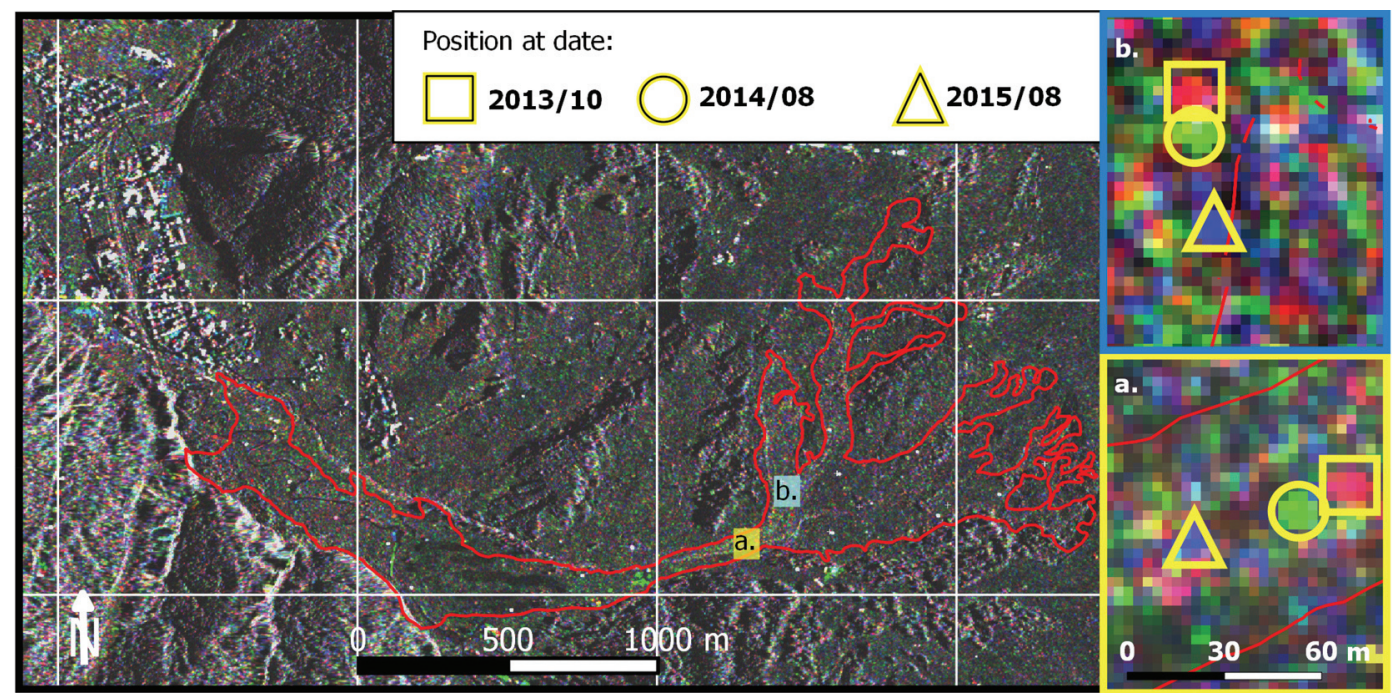

Figure 2. RGB composite image for change detection aims depicting changes occurred within the period 10/2013 to 08/2015. (red channel: 2013/10; green channel: 2014/08; blue channel: 2015/08). Squares a) and b) show occurred displacements of CR54 and CR51.

Table 1. Planar displacements obtained by offset-tracking.

\begin{tabular}{rlll}
\hline & $\begin{array}{l}\text { Displacement } \\
\text { direction* }\end{array}$ & $\begin{array}{l}\text { Displacement } \\
\text { module }\end{array}$ & \\
\cline { 2 - 3 } Point ID & degrees & meters & $\begin{array}{l}\text { Correlation } \\
\text { value }\end{array}$ \\
\hline 4 & 315 & 0.53 & 0.76 \\
6 & 315 & 0.53 & 0.85 \\
8 & 252 & 1.19 & 0.70 \\
23 & 270 & 0.38 & 0.80 \\
25 & 252 & 1.19 & 0.73 \\
28 & 225 & 0.53 & 0.77 \\
49 & 225 & 0.53 & 0.82 \\
51 & 172 & 40.52 & 0.68 \\
53 & 279 & 2.28 & 0.74 \\
54 & 249 & 5.22 & 0.75 \\
55 & 250 & 50.78 & 0.70 \\
56 & 162 & 5.93 & 0.75 \\
58 & 135 & 0.53 & 0.76 \\
\hline
\end{tabular}

* Azimuth angle respect to North in clockwise direction.

combined in a RGB view by using a red color scale for the amplitude in the Oct-2013 image, a blue scale for the Aug-2014 image and a green scale for the Aug2015 image. In Figures 2a and 2b, details of the main map are presented showing the changing posi-tion of the highly reflective CR nr.54 and 51 in the different images. In this kind of situation, i.e. highly reflective objects that can be identified in the images, the OT algorithm has been capable of estimating displacements by cross - correlation. This was possible for all the CR except for three of them (CR 11, 13 and 57), for which the OT method could not determine a sufficient cross-correlation value for offset estimation. For all other CRs, the correlation value has been always above or equal to 0.7 (Table 1).

The offset-tracking technique has detected planar displacements of CR ranging between $1 \times 10^{-1}$ and $1 \times 10^{1} \mathrm{~m}$ (Table 1). Recorded displacement directions are generally consistent with measurement of the past years and confirm the overall geomorphic model of the Corvara landslide (Figure 3). Exceptions are CR 58 and CR8, that show azimuth direction inconsistent with the expected direction of movements. The reason for this discrepancy is analyzed in the discussion section by using the D-GPS validation dataset as reference.

\section{VALIDATION AND DISCUSSION}

The CR displacements measured by OT method have been validated using the high precision D-GPS dataset. Error quantification of the pixel offset method in comparison to D-GPS positioning of the residuals of the azimuth angle and the module of the cumulative displacement vectors have been computed. In Figure 4, a polar representation of the two cumulative displacements is displayed in order to evidence the differences between OT and D-GPS results. This comparison highlights that the lower the module of the displacement vector is, the higher the error of the azimuth and module of displacement obtained by OT method are. This result 


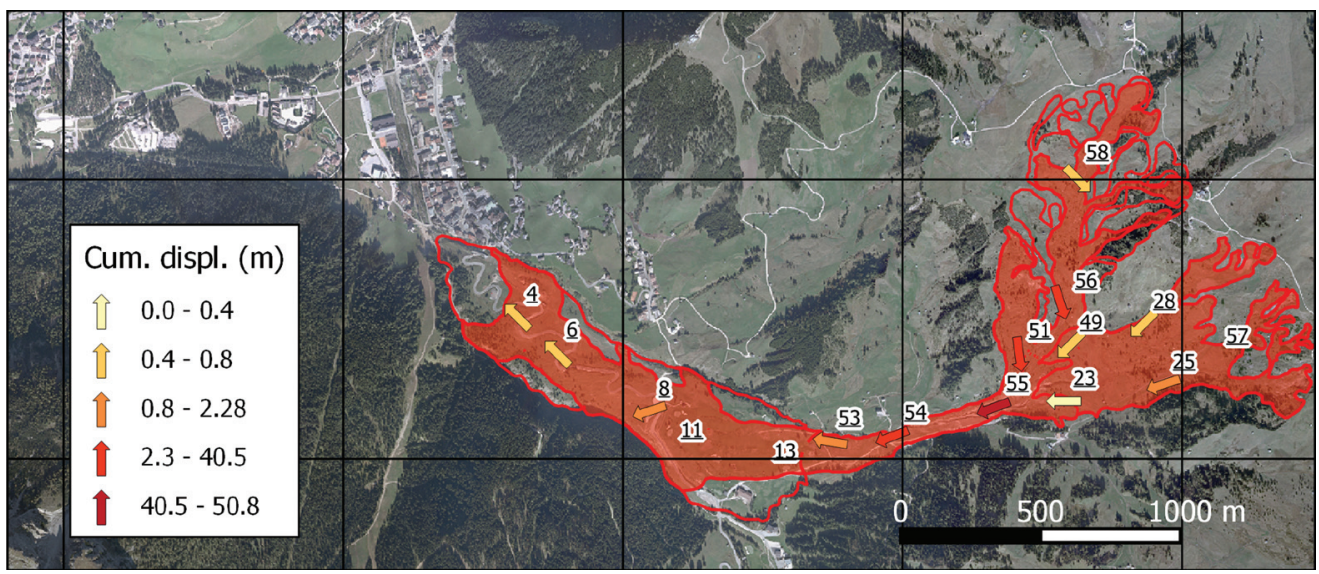

Figure 3. Planar displacement resulting from the offset-tracking technique for the period 10/2013-08/2015.

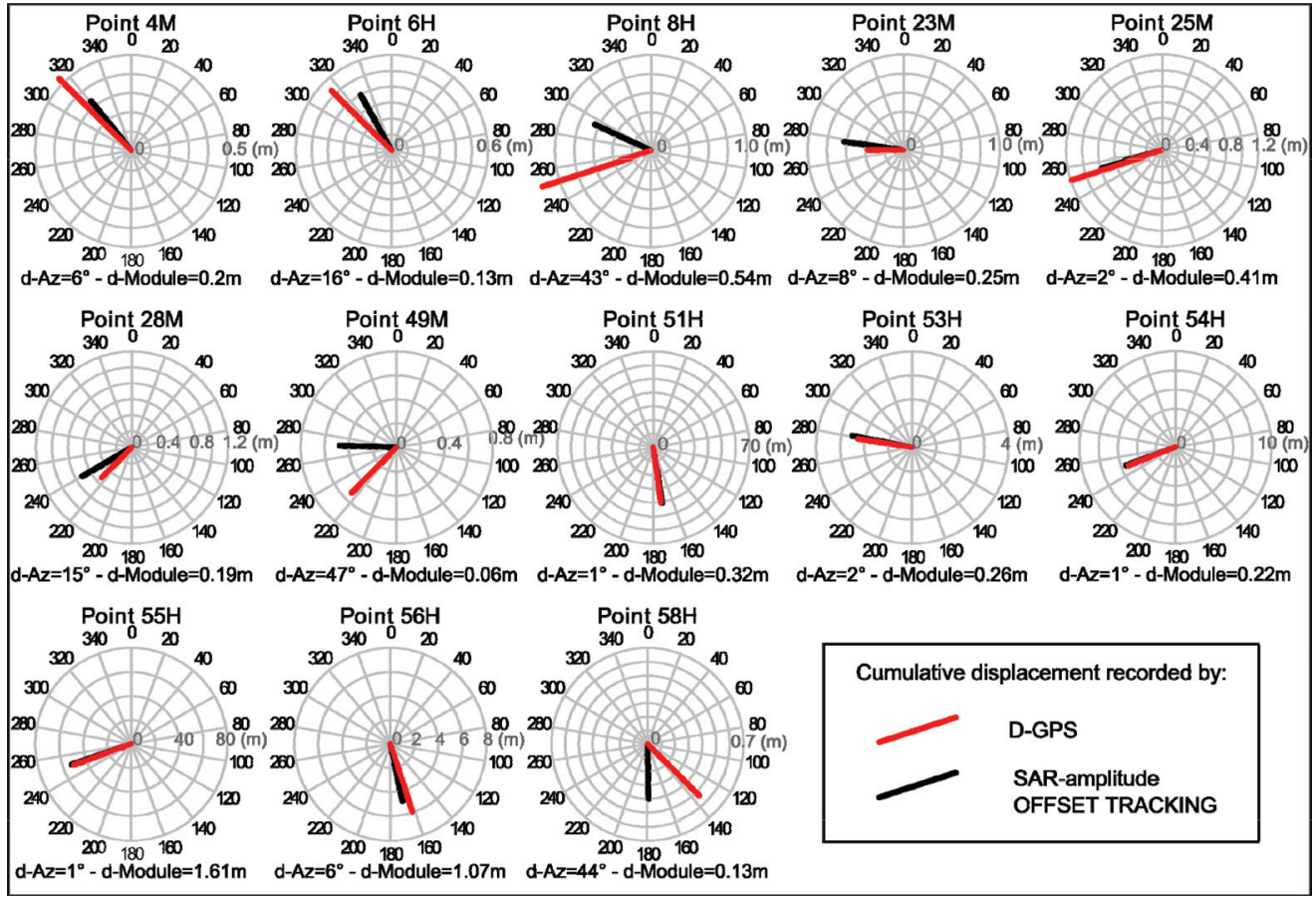

Figure 4. Polar plot of displacement recorded by offset-tracking technique versus D-GPS validation dataset.

is determined by the relative low resolution of the OT method $(0.375 \mathrm{~m})$, that makes the assessment of low displacement values affected by large discrepancies with respect to D-GPS measurements.

To highlight the dependency of the accuracy of OT with the module of displacement, the percentage of difference between OT and D-GPS displacement has been plotted against the module of displacement determined by D-GPS (Figure 5). The plot and the trend line depicted in red in Figure 5 , shows that with the increase of the measured displacement, the percentage of error decreases from $80 \%$ for a sub-metric displacement to a $1 \%$ for a 40 to 50 meters of displacement. Thus with displacements close to the CSK image resolution, the OT results are affected by larger errors. 


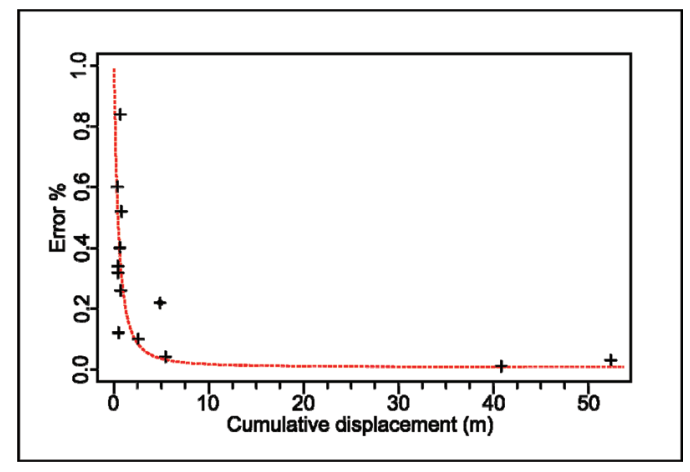

Figure 5. Offset-tracking percentage error with respect to displacement recorded.

\section{CONCLUSION}

In this work, we showed that the application of the OT technique using SAR amplitude images for landslide monitoring is possible. Due to the availability of a high precision D-GPS validation dataset, it was also possible to determine that errors are quite low (around 20\%) for displacements larger than $0.7 \mathrm{~m}$. On the other hand, for smaller displacements, OT results are affected by too large errors in order to consider them reliable for monitoring.

Due to its high reliability in measuring metric displacements, OT technique confirms its potential complementary role with respect to multi-temporal advanced SAR interferometry, that with current $\mathrm{X}$-Band and $\mathrm{C}$-Band is performing at its best for displacements in the order of the centimeter (Barboux, et al. 2015, Notti et al. 2015). As a matter of fact, by the mutual application of both SAR-based monitoring techniques, it is possible to cover a wider ranges of displacement rates within an unstable slope. An additional benefit of OT based on SAR amplitude images in comparison to advanced multiinterferometry, is its capacity to measure displacements along a North-South direction, something that InSAR interferometry is not capable of doing.

\section{ACKNOWLEDGMENT}

Work carried out using COSMO-SkyMed Product - CASI - Agenzia Spaziale Italiana - 2013. All rights Reserved.

\section{REFERENCES}

Barboux C., Strozzi T., Delaloye R., Wegmüller U., Collet C. 2015. Mapping slope movements in Alpine environments using TerraSAR-X interferometric methods. in: ISPRS Journal of Photogrammetry and Remote Sensing, 109, 178-192.

Casu, F., Manconi, A., Pepe, A., Lanari, R. 2011. Deformation time-series generation in areas characterized by large displacement dynamics: The SAR amplitude pixel-offset SBAS technique. IEEE Trans. Geosci. Remote Sens. 49, 2752-2763. doi:10.1109/ TGRS.2010.2104325

Corsini A., Pasuto A, Soldati M. 2000. Landslides and climate change in the Alps since Late-glacial: evidence of the case studies in the Dolomites (Italy), In: Bromhead E., Dixon N., Ibsen ML. Landslides in Research, Theory and Practice, Thomas Telford Publishing, London, pp. 329-334.

Corsini, A., Iasio, C., Mair, V. 2012. Overview of 2001-08 GPS monitoring at the Corvara landslide and perspectives from 2010-11 use of HR X-band SAR ( Dolomites, Italy ), in: Eberhardt (Ed.), Landslides and Engineered Slopes: Protecting Society through Improved Understanding. pp. 1353-1358.

Corsini, A., Marchetti, M., Soldati, M. 2001. Holocene slope dynamics in the area of Corvara in Badia (Dolomites, Italy). Geografia Fisica e Dinamica Quaternaria 24, 127-139

Corsini, A., Mulas, M., Marcato, G., Chinellato, G., Mair, V. 2015. Acceleration of large active earthflows triggered by massive snow accumulation events: evidences from monitoring the Corvara landslide in early 2014 ( Dolomites, Italy ), in: Geophysical Research Abstracts. p. 7357

Corsini, A., Pasuto, A., Soldati, M. 1999. Geomorphological investigation and management of the Corvara landslide (Dolomites, Italy). Transactions-Japanese Geomorphological Union 20, 169-186

Corsini, A., Pasuto, A., Soldati, M., Zannoni, A. 2005. Field monitoring of the Corvara landslide (Dolomites, Italy) and its relevance for hazard assessment. Geomorphology 66, 149-165. doi:10.1016/j. geomorph.2004.09.012

Heid, T. and Kääb, A. 2012. Evaluation of existing image matching methods for deriving glacier surface displacements globally from optical satellite imagery Remote Sensing of Environment, 118, 339-355.

Kääb A. 2002: Monitoring high-mountain terrain deformation from repeated air- and spaceborne optical data: examples using digital aerial imagery and ASTER data. ISPRS Journal of Photogrammetry \& Remote Sensing. 57 (1-2). 39-52.

Kääb A. and Vollmer M. 2000. Surface geometry, thickness changes and flow fields on creeping mountain permafrost: automatic extraction by digital image analysis. Permafrost and Periglacial Processes.11, 315-326.

Mair, V., Mulas, M., Chinellato, G., Corsini, A., Iasio, C., Mosna, D., Strada, C., Thieabes, B., submitted. Developing X-band corner reflectors for multitechnological monitoring of ground displacement in alpine environments. in: Proceedings of the 13th Congress INTERPRAEVENT 2016.

Manconi A., Casu F., Ardizzone F., Bonano M., Cardinali M., De Luca C., ... \& Guzzetti F. 2014. Brief Communication: Rapid mapping of landslide events: the 3 December 2013 Montescaglioso landslide, Italy. in: Natural Hazards and Earth System Science, 14(7), $1835-1841$. 
Mulas, M., Corsini, A., Soldati, M., Marcato, G., Pasuto, A. 2015a. Integration of X-band SAR interferometry, continuous and periodic D-GPS and in-place inclinometers to characterize and monitor a deep-seated earthslide in the Dolomites (Italy), in: Geophysical Research Abstracts. 17:5784.

Mulas, M., Petitta, M., Corsini, A., Schneiderbauer, S., Mair, V., Iasio, C. 2015b. Long-term monitoring of a deep-seated, slow-moving landslide by mean of $\mathrm{C}$-band and X-band advanced interferometric products: the Corvara in Badia case study (Dolomites, Italy). ISPRS - Int. Arch. Photogramm. Remote Sens. Spat. Inf. Sci. XL-7/W3, 827-829. doi:10.5194/ isprsarchives-XL-7-W3-827-2015

Mulas, M., Petitta, M., Brazanti, M., Benedetti, E., Corsini, A., Iasio, C. 2012. Spatio-temporal analysis of SAR based time series for slope instability characterization: the Corvara in Badia landslide ( Dolomites, Italy ), in: IEEE GOLD REMOTE SENSING 2012. p. 10342.

Notti D., Herrera G., Bianchini S., Meisina C., GarcíaDavalillo J.C., Zucca F. 2014. A methodology for improving landslide PSI data analysis. in: International Journal of Remote Sensing, 35(6), 2186-2214.

Shi, X., Zhang, L., Balz, T., Liao, M. 2015. Landslide deformation monitoring using point-like target offset tracking with multi-mode high-resolution TerraSAR-X data. ISPRS J. Photogramm. Remote Sens. 105, 128-140. doi:10.1016/j.isprsjprs.2015.03.017.

Singleton A., Li Z., Hoey T., and Muller J.-P. 2014. Evaluating subpixel offset techniques as an alternative to D-InSAR for monitoring episodic landslide movements in vegetated terrain, in: Remote Sens. Environ., 147, 133-144, doi:10.1016/j.rse.2014.03.003. 